\title{
Voltage Control and Power Oscillation Damping Of Multi-Area Power System Using StaticSynchronous Series Compensator
}

\author{
PramodKumar, K. Namrata \\ Deptt.of Electrical Engg. NIT Jamshedpur (Jharkhand), India
}

\begin{abstract}
The main aim of this paper is to damp out power system oscillations, which has been recognized as one of the major concerns in power system operation. In a Static Synchronous Series Compensator (SSSC), a controllable AC voltage is generated by a voltage-source converter. There are two control channels for controlling the magnitude and phase of the voltage. This paper describes the damping of power oscillations by static synchronous series compensator (SSSC) based damping controllers. The advantage of this approach is that it can handle the nonlinearities, at the same time it is faster than other conventional controllers and it improve the reactive power of the system. Simulation studies are carried out in Matlab/Simulink environment to evaluate the effectiveness of the proposed Static synchronous series compensator (SSSC) of multi-area power system. Results show that the proposed SSSC based damping controllers improve the damping performance of the in the event of a major disturbance.
\end{abstract}

Key Words:- Flexible AC Transmission System (FACTS), Static Synchronous Series Compensator (SSSC), Power Oscillation Damping (POD) controller.

\section{Introduction}

During the last decade, a number of control devices under the term FACTS technology have been proposed and implemented. Application of FACTS devices in power systems, leads to better performance of system in many aspects [1-5]. Voltage stability, voltage regulation and power system stability, damping can be improved by using these devices and their proper control.

There are various forms of FACTS devices, some of which are connected in series with a line and the others are connected in shunt or a combination ofseries and shunt. The FACTS technology is not a single high power controller but rather a collection of controllers which can be applied individually or in coordination with other to control one or more of the inter related system parameters like voltage, current, impedance, phase angle and damping of oscillations at various frequencies below the rated frequency.

Among all FACTS devices, static synchronous series compensators (SSSC) plays much more important role in reactive power compensation and voltage support because of its attractive steady state performance and operating characteristics[6-7].

The power system is a highly nonlinear system that operates in a constantly changing environment; loads, generator outputs, topology, and key operating parameters change continually [8-9]. When subjected to a transient disturbance, the stability of the system depends on the nature of the disturbance as well as the initial operating condition. The disturbance may be small or large. Small disturbances in the form of load changes occur continually, and the system adjusts to the changing conditions. The system must be able to operate satisfactorily under these conditions and successfully meet the load demand. It must also be able to survive numerous disturbances of a severe nature, such as short-circuit on a transmission line or loss of a large generator.Oscillations of generator angle or line angle are generally associated with transmission system disturbances and can occur due to step changes in load, sudden change of generator output, transmission line switching, and short circuits[10-11]. Depending on the characteristics of the power system, the oscillations may last for 3-20 seconds after a severe fault. Drawn out oscillations that last for a few seconds or more are usually the result of very light damping in the system and are pronounced at power transfers thatapproach the line's stability limit. During such angular oscillation period, significant cycle variations in voltages, currents, and transmission line flows will take place. It is important to damp these oscillations as quickly as possible because they cause mechanical wear in power plants and many power quality problems. The system is also vulnerable if further disturbances occur. To improve the voltage stability and the damping of oscillations in power systems, supplementary control laws can be applied to existing devices. These supplementary actions are referred to as voltage stability and power oscillation damping (POD) control. In this work, voltage stability and POD control has been applied to Static synchronous series compensator (SSSC).The SSSC using a voltage source converter to inject a controllable voltage in quadrature with the line current of a power network is able to rapidly provide both capacitive and inductive impedance compensation independent of the power line current[12-14]. Moreover, a SSSC with a suitably designed external damping controller can be used to improve the damping of the low 
frequency power oscillations in a power network. These features make the SSSC an attractive FACTS device for power flow control, power oscillation damping and improving transient stability.

In this paper, the damping performance of a two-machine power system is compared for the cases of with and without SSSC based damping controllers in the event of a 3-phase short circuit faults and 2-phase ground faults. Simulation results show that in damping power system oscillations, the SSSC with POD controller is more effective than the SSSC without POD controller.

\section{Power system under study}

To design and optimize the SSSC-based damping controller, a multi-area power system with SSSC, shown in Fig.1, is considered. It is similar to the power systems used in references. The system consists of two generators divided in two subsystems and are connected via an intertie. Following a disturbance, the two subsystems swing against each other resulting in instability. To improve the stability the line is sectionalized and a SSSC is in between the bus-line 1 and 2 . In the Figure, $G_{1}$ and $G_{2}$ represent the generators; $T / F_{1}$ and $T / F_{2}$ represent the transformers in the bus-line1 and bus-line 2 respectively.

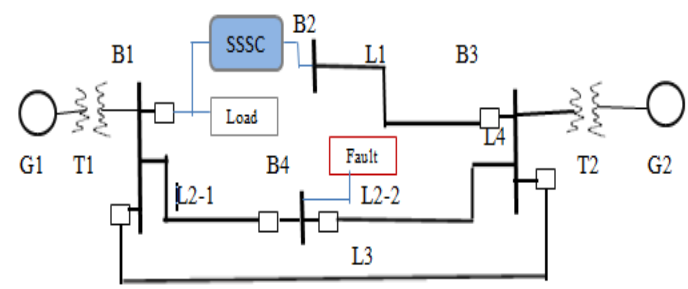

Fig. 1 Single line diagram of a two-machine power systemwith SSSC

The SSSC injected voltage reference is normally set by a POD (Power oscillation damping) controller. In general, the structure of a FACTS POD controller is shown in Fig.2. It involves a transfer function consisting of an amplification block, a washout block and two lead-lag blocks and an output limiter. Commonly, the local signals of FACTS devices are always applied for the damping control. The inputs to the POD controller are the voltage at bus B1 and the current flowing in the line $\mathrm{L} 1$.

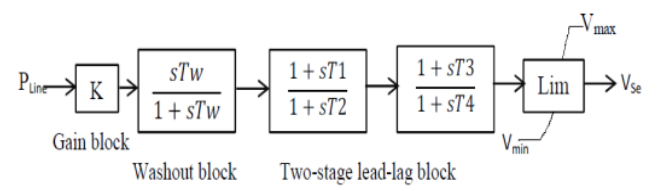

Fig. 2 The structure of a simple FACTS POD controller

\section{Basic Operating Princples of SSSC}

Below Fig. 3 shows a functional model of the SSSC where the dc capacitor has been replaced by an energy storage device such as a high energy battery installation to allow active as well as reactive power exchanges with the ac system. It comprises a voltage source inverter and a coupling transformer that is used to insert the ac output voltage of the inverter in series with the transmission line. The SSSC's output voltage magnitude and phase angle can be varied in a controlled manner to influence power flows in a transmission line. The phase displacement of the inserted voltage $V_{p q}$, with respect to the transmission line current line $\mathrm{I}_{\text {line, }}$, determines the exchange of active and reactive power with the ac system.

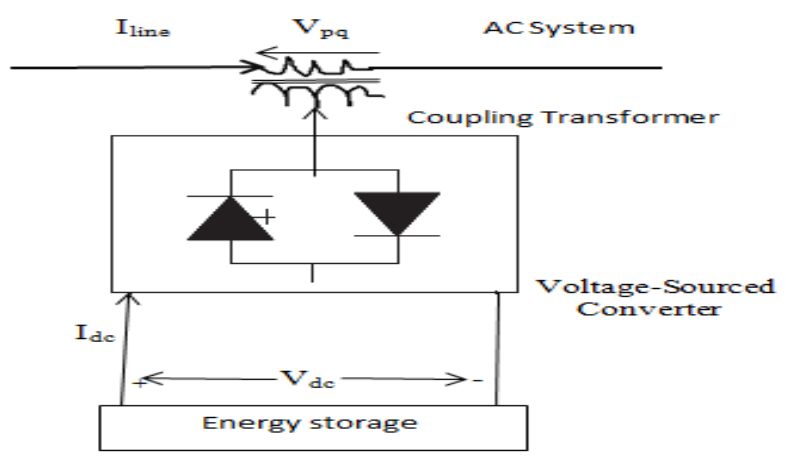

Fig. 3 Functional model of SSSC 
(a)

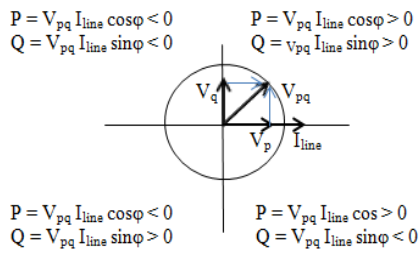

(b)

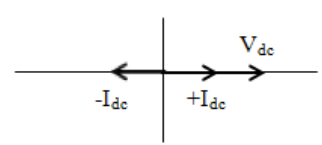

Fig. 4 SSSC phasor diagram

Theoretically, SSSC operation in each of the four quadrants is possible, Theoretically, SSSC operation in each of the four quadrants is possible, but there are some limitations to the injected SSSC voltage due to operating constraints of practical power system.

In capacitive mode, the injected SSSC voltage is made to lag the transmission line current by $90^{\circ}$; in this case, the SSSC operation is similar to the operation of a series capacitor with variable capacitance $\mathrm{kXc}$, i.e., $\mathrm{V}_{\mathrm{pq}}=-\mathrm{jKX} \mathrm{K}_{\mathrm{c}} \mathrm{I}_{\text {line }}$, where $\mathrm{k}$ is a variable.

\subsection{Rating of the SSSC}

The SSSC can provide capacitive or inductive compensating voltage independent of the line current. The VA rating of the SSSC (solid-state inverter and coupling transformer) is simplythe product of the maximum line current (at which compensation is still desired) and the maximum series compensating voltage: VA = $I_{\max } V_{\max }$. An SSSC of 1 p.u. VA rating covers a control range corresponding to 2 p.u. compensating VARs, that is the control range is continuous from -1 p.u. (inductive) VARs to +1 p.u. (capacitive) VARs.

\subsection{Internal Controls}

From the standpoint of output voltage control, converters may be categorized as "directly" and "indirectly" controlled. For directly controlled converters both the angular position and the magnitude of the output voltage are controllable by appropriate valve (on and off) gating. For indirectly controlled converters only the angular position of the output voltage is controllable by valve gating; the magnitude remains proportional to the de terminal voltage. The control method of maintaining a quadrature relationship between the instantaneous convertervoltage and line current vectors, to provide reactive series compensation and handle SSR, can be implemented with an indirectly controlled converter. The method of maintaining a single frequency synchronous (i.e. fundamental) output independent of dc terminal voltage variation requires a directly controlled converter. Although high power directly controlled converters are more difficult and costly to implement than indirectly controlled converters (because their greater control flexibility is usually associated with some penalty in terms of increased losses, greater circuit complexity, and/or increased harmonic content in the output),nevertheless they can be realized to meet practical utility requirements.

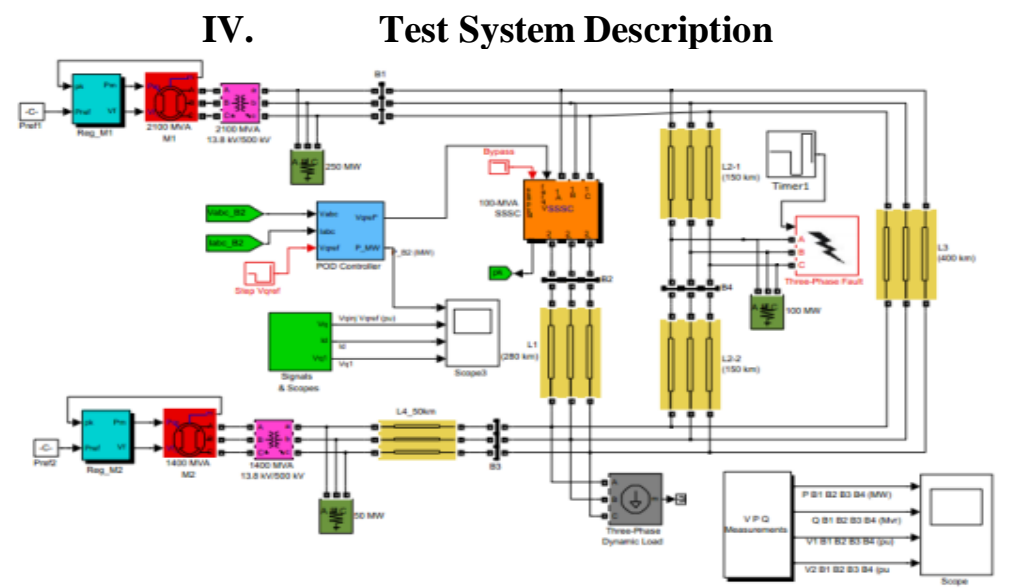

Fig. 5 Static Synchronous Series Compensator (SSSC) used for power oscillation damping 
In this paper, the SSSC is used to damp power oscillation on a power grid following a three-phase fault and L-L-G fault which is more severe. The power grid consists of two power generation substations and one major load centre at bus B3. The first power generation substation (M1) has a rating of $2100 \mathrm{MVA}$; representing 6 machines of $350 \mathrm{MVA}$ and the other one (M2) has a rating of $1400 \mathrm{MVA}$, representing 4machines of 350 MVA. The load centre of approximately $2200 \mathrm{MW}$ is modelled using a dynamic load model where the active \& reactive power absorbed by the load is a function of the system voltage. The generation substation M1 is connected to this load by two transmission lines L1, L2 and L3. L1 is 280-km long and L2 is split in two segments of $150 \mathrm{~km}$ each in order to simulate a three-phase fault and L-L-G fault (using a fault breaker). The generation substation M2 is also connected to the load by a $50-\mathrm{km}$ line (L4). When the SSSC is bypass, the power flow towards this major load is as follows: $664 \mathrm{MW}$ flow on L1 (measured at bus B2), 563 MW flow on L2 (measured at B4) and 990 MW flow on L4 (measured at B3). The SSSC, located at bus B1, is in series with line L1.

\section{Simulation and Results}

The simulation results are mainly divided two sections. Thus, Section A discusses results for SSSC Dynamic responses for three-phase solid fault and two-phase ground faults without and with POD controller. The results obtained for the test system with three-phase solid fault and two-phase ground faults applied at Bus 4 without and with phase controlled SSSC are presented in Section B.

\section{A. SSSC Dynamic Responses}

Initially $\mathrm{V}_{\text {qref }}$ is set to $0 \mathrm{pu}$; at $\mathrm{t}=3 \mathrm{~s}, \mathrm{~V}_{\text {qref }}$ is set to $-0.08 \mathrm{pu}$ (SSSC inductive); then at $\mathrm{t}=9 \mathrm{~s}, \mathrm{~V}_{\text {qref }}$ is set to $0.08 \mathrm{pu}$ (SSSC capacitive). Also, the fault breaker will not operate during the simulation. In below Fig.6, the first graph shows the active power flow $\mathrm{P} \_\mathrm{B} 2$ on line L1, measured at bus B2. The second graph shows the $\mathrm{V}_{\mathrm{qref}}$ signal along with the measured injected voltage by the SSSC. The third graph shows the $\mathrm{I}_{\mathrm{d}}$ current of SSSC and fourth graph shows the magnitude of $\mathrm{V}_{\mathrm{q}}$.

We see on the transmitted power (P_B2signal) so, we reduce the "Maximum rate of change for $\mathrm{V}_{\mathrm{qref}}(\mathrm{pu} / \mathrm{s})$ )" from 3 to 0.08 . A 70 MVAr $30 \mathrm{kV} \mathrm{SSSC}$ is inserted in the test system between Bus 1and Bus 2, in series with the transmission line with higher impedance.

Case- (a) LLL fault without POD controller

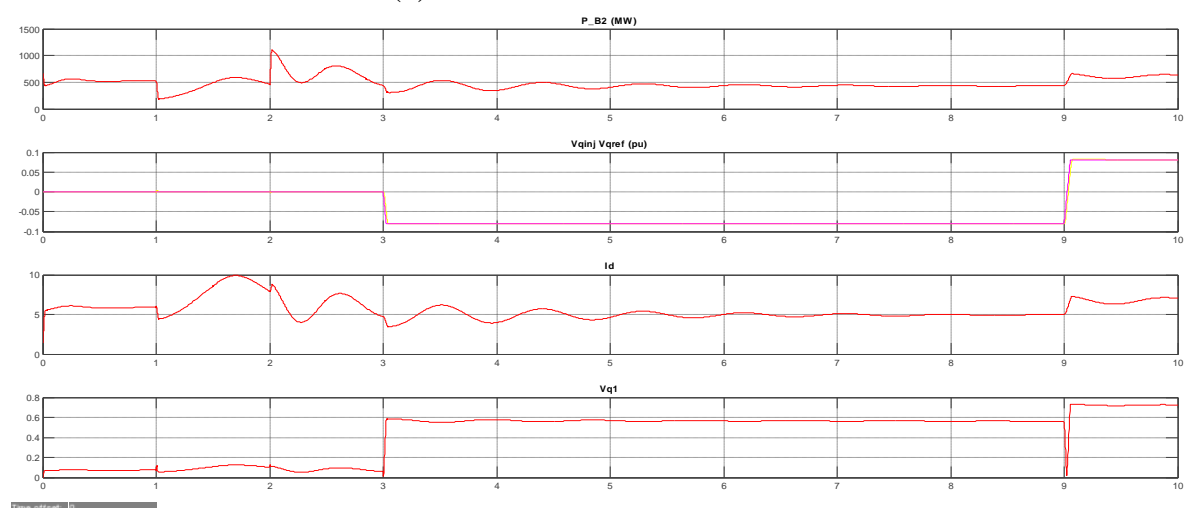

Fig.6 (a) Dynamic response of SSSC for LLL fault without POD controller

Case- (b) LLL fault with POD controller

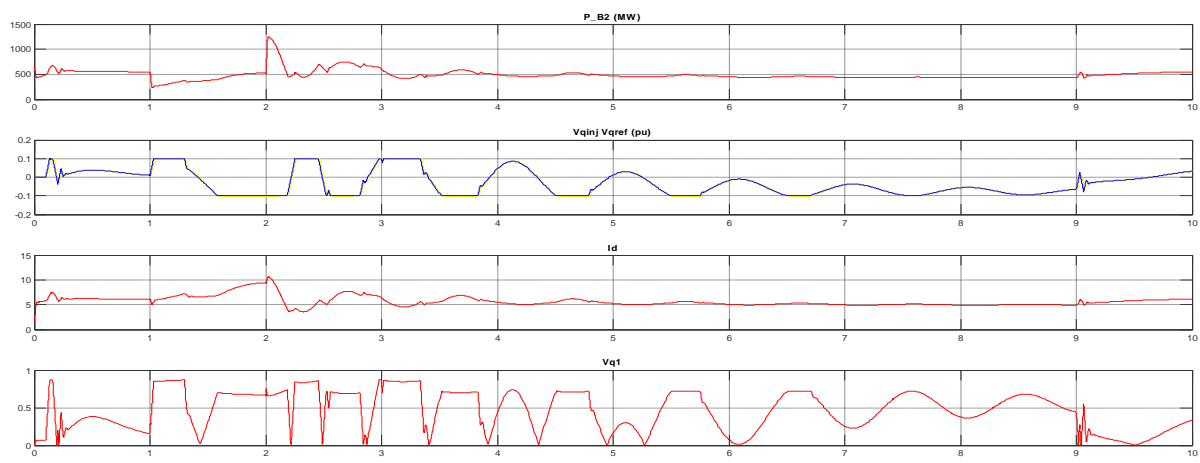

Fig. 6 (b) Dynamic response of SSSC for LLL fault with POD controller 
Case- (c) LLG fault without POD controller
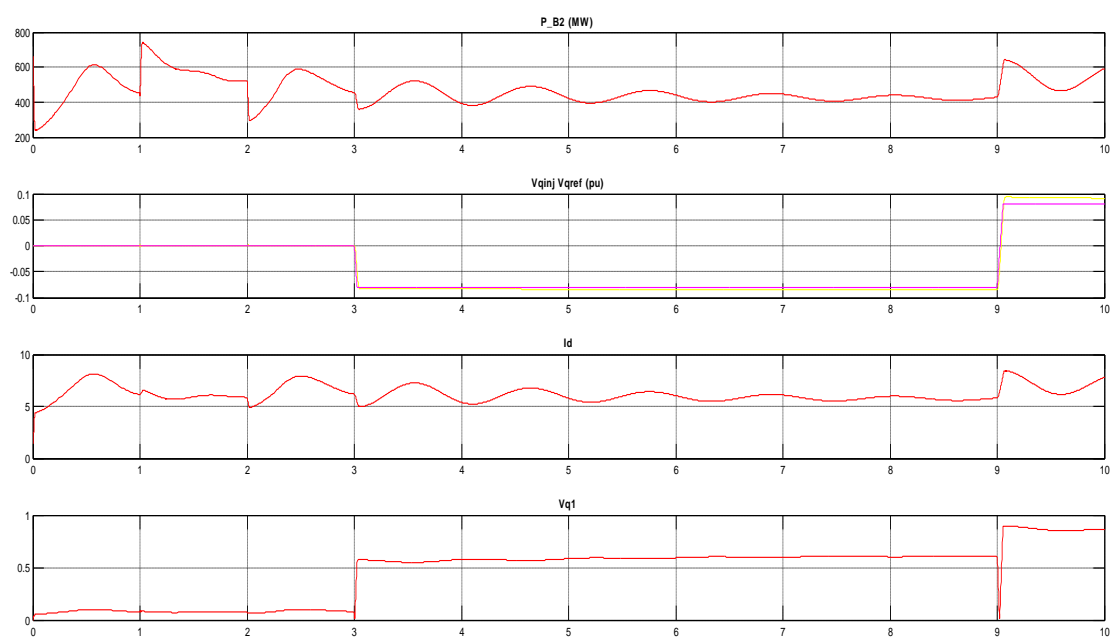

Fig. 6 (c) Dynamic response of SSSC for LLG fault without POD controller

Case- (d) LLG fault with POD controller

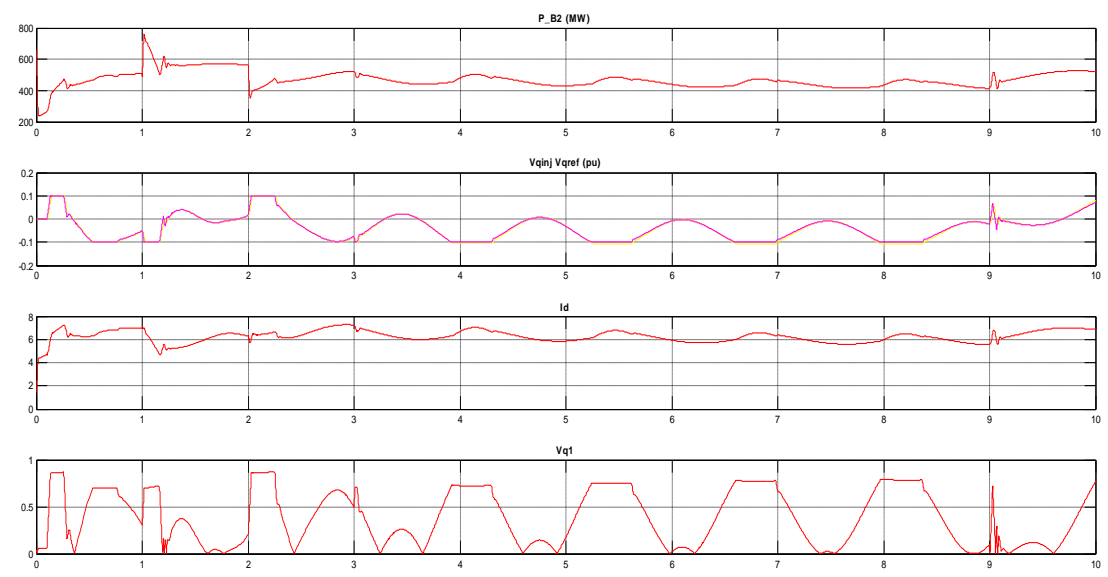

Fig. 6 (d) Dynamic response of SSSC for LLG fault with POD controller

\section{B. Test system simulated waveform}

In this test, simulation is performed without and with SSSC controller. Below Fig.7 indicates a threephase solid faults and two phase ground faults are applied at Bus 4 that its transition times should be set as follows: [ 50/50 100/50]; this means that the fault will be applied at 2 s and will last for 50 cycles. The simulation shows active power, reactive power, magnitude and phase of voltage at bus B1, B2, B3and B4 respectively in each Fig.7.

Case (a) LLL fault without POD controller

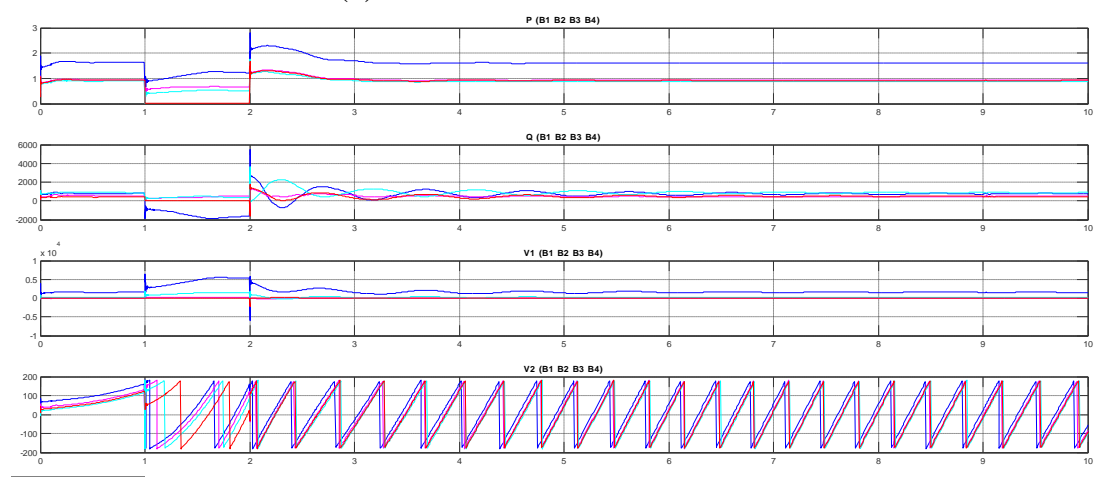

Fig.7 (a) Simulated wave form for LLL fault without POD controller 

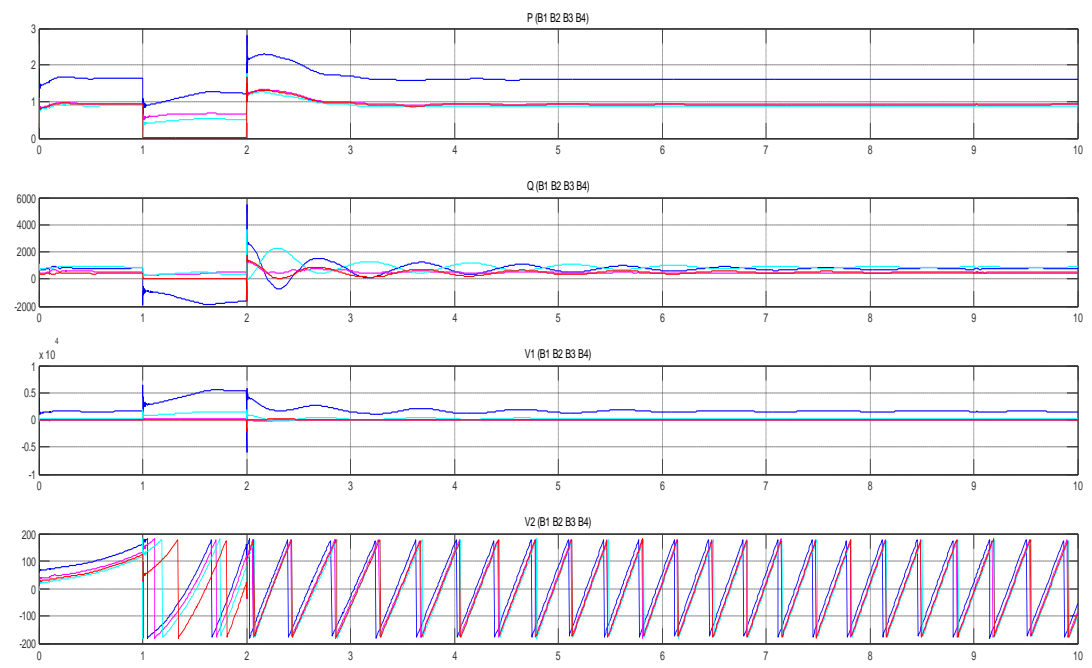

Fig. 7(b) Simulated wave-form for LLL fault with POD controller

Case (c) LLG fault without POD controller
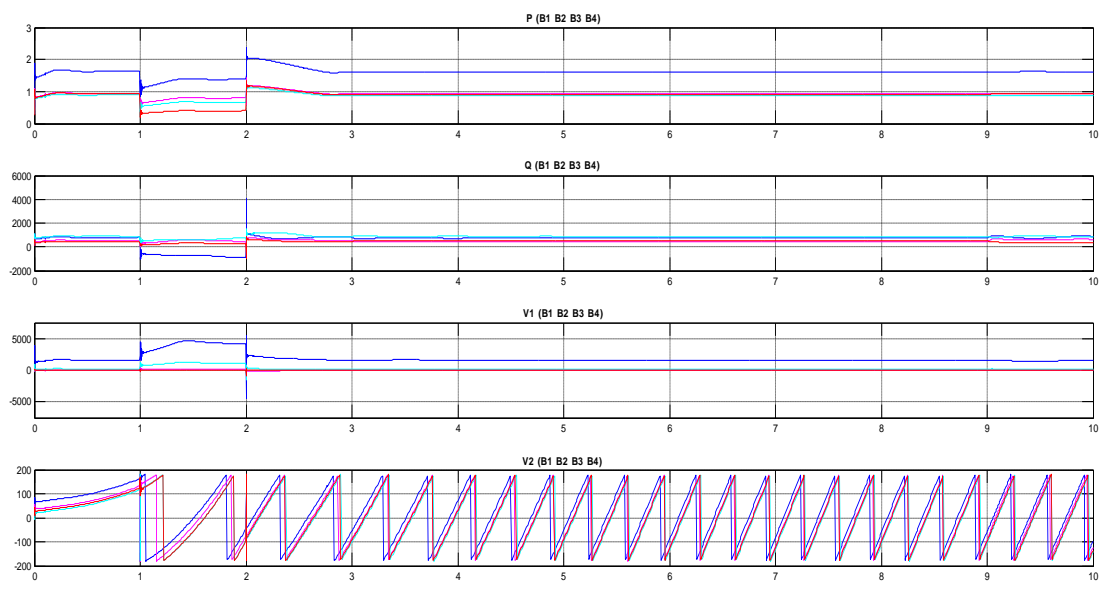

Fig. 7(c) Simulated wave-form for LLG fault withoutPOD controller

Case (d) LLG fault with POD controller
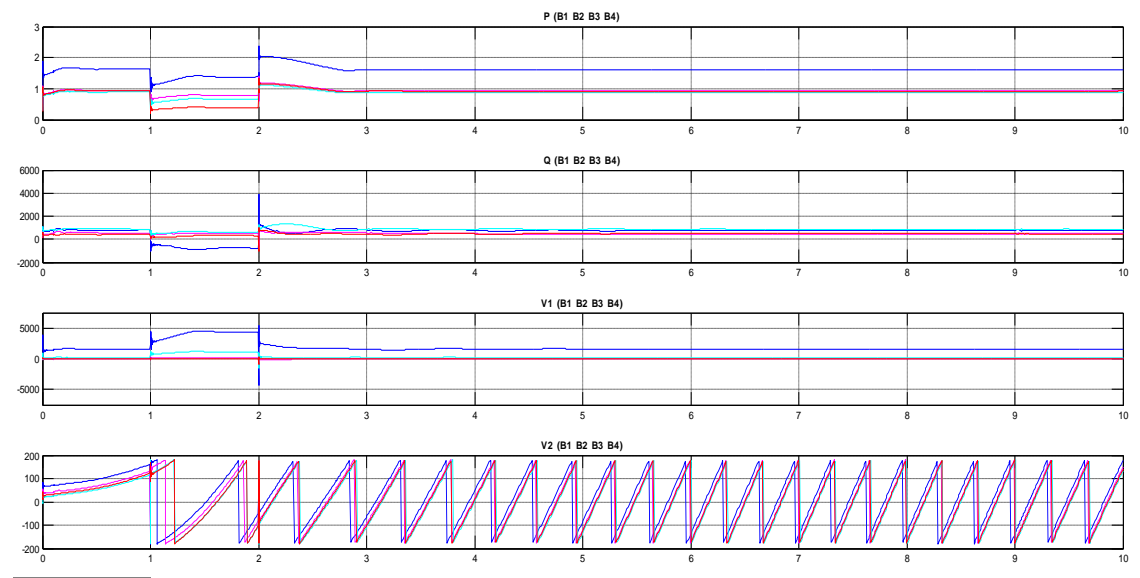

Fig. 7(d)Simulated wave-form for LLG fault with POD controller 
VI.

CONCLUSION

In this paper, the simulation of a two-machine power system model with Static synchronous series compensator (SSSC) based damping controllers in the presence of a three-phase short circuit fault and twophase ground fault are considered. The results show that the power system oscillations are damped out very quickly with the help of SSSC based damping controllers in few seconds. The studies, which include detailed techniques of twelve-pulse and PWM controlled SSSC, are conducted and the control circuits are presented. The SSSC operating conditions and constraints are compared to the operating conditions of other FACTS devices, showing that the SSSC offers several advantages over others. The dc voltage pre-set value in PWM-based controllers has to be carefully selected. As the modulation ratio lies between zero and one, the dc voltage should not be lower than the maximum of the requested SSSC output phase voltage in order to obtain proper control. On the other hand, if the dc side voltage is too high, the rating of both the GTO valves and dc capacitor has to be increased, which means higher installation costs. Not only that, a higher dc side voltage means a lower amplitude modulation ratio and the lower modulation ratio results in higher harmonic distortion. Phase control allows the dc voltage to change according to the power system conditions, which is clearly advantageous, but it requires a more complicated controller and special and costly series transformers. The results show that the use of SSSC is having improved dynamic response and at the same time faster than other conventional controllers. Moreover, this approach is also simple and easy to be realized in power systems.

\section{Appendix}

A complete list of parameters used appears in the default options of Sim Power Systems in the above block diagram model. All data are in p.u. unless specified otherwise.

\begin{tabular}{|c|c|}
\hline Generator & $\begin{array}{l}\mathrm{S}_{\mathrm{B} 1}=2100 \mathrm{MVA}, \mathrm{S}_{\mathrm{B} 2}=1400 \mathrm{MVA}, \mathrm{V}_{\mathrm{B}}=13.8 \mathrm{kV}, \mathrm{f}= \\
50 \mathrm{H}_{\mathrm{Z}}, \mathrm{X}_{\mathrm{d}}=1.3,05, \mathrm{X}^{\prime} \mathrm{d}=0.296, \mathrm{X}^{\prime \prime}=0.252, \mathrm{X}_{\mathrm{q}}=0474, \\
\mathrm{X}_{\mathrm{q}}^{\prime}=0.243, \mathrm{X}_{\mathrm{q}}^{\prime}=0.18, \mathrm{~T}_{\mathrm{d}}=1.01 \mathrm{~s}, \mathrm{~T}_{\mathrm{d}}=0.053 \mathrm{~s}, \mathrm{~T}_{\mathrm{qo}}= \\
0.1 \mathrm{~s}, \mathrm{P}_{\mathrm{e} 1}=0.3048, \mathrm{P}_{\mathrm{e} 2}=0.2095, \mathrm{R}_{\mathrm{s}}=2.8544 \mathrm{e}^{-3}, \mathrm{H}= \\
3.7 \mathrm{~s}, \mathrm{P}=32\end{array}$ \\
\hline Loads & $\begin{array}{l}\text { Load } 1=250 \mathrm{MW}+100 \mathrm{MVA}, \text { Load } 2=50 \mathrm{MW}, \text { Load } 3 \\
=100 \mathrm{MW}\end{array}$ \\
\hline Transformer & $\begin{array}{l}\mathrm{S}_{\mathrm{BT1}}=2100 \mathrm{MVA}, \mathrm{S}_{\mathrm{BT2}}=1400 \mathrm{MVA}, 13.8 / 500 \mathrm{kV}, \\
50 \mathrm{H}_{\mathrm{Z}}, \mathrm{R}_{\mathrm{m}}=500, \mathrm{R}_{2}=0.002, \mathrm{~L}_{\mathrm{m}}=500, \mathrm{~L} 1=0, \mathrm{~L} 2= \\
0.12, \mathrm{D} 1 / \mathrm{Yg} \text { connection }\end{array}$ \\
\hline Transmission Lines & $\begin{array}{l}3-\mathrm{Ph}, 50 \mathrm{~Hz}, \mathrm{~L}_{1}=280 \mathrm{~km}, \mathrm{~L}_{4}=50 \mathrm{~km}, \mathrm{~L}_{2-1}=150 \mathrm{~km}, \mathrm{~L}_{2} \\
2=150 \mathrm{~km}, \mathrm{~L}_{3-1}=200 \mathrm{~km}, \mathrm{~L}_{3} 2=200 \mathrm{~km}, \mathrm{R} 1= \\
0.02546 \Omega / \mathrm{km}, \mathrm{R}_{0}=0.3864 \Omega / \mathrm{km}_{1} \mathrm{~L}_{1}=0.9337 \mathrm{e}^{-3} \mathrm{H} / \mathrm{km}, \\
\mathrm{L}_{0}=4.1264 \mathrm{e}^{-3} \mathrm{H} / \mathrm{km}, \mathrm{C}_{1}=12.74 \mathrm{e}^{-3} \mathrm{~F} / \mathrm{km}, \mathrm{C}_{0}=7.75 \mathrm{e}^{-3} \mathrm{~F} \\
/ \mathrm{km}\end{array}$ \\
\hline $\begin{array}{l}\text { Hydraulic Turbine } \\
\text { and Governor }\end{array}$ & $\begin{array}{l}\mathrm{Ka}=3.33, \mathrm{Ta}=0.07, \mathrm{Gmin}=0.01, \mathrm{Gmax}=0.97518, \mathrm{~V} \\
\mathrm{gmin}=-0.1 \mathrm{pu} / \mathrm{s}, \mathrm{Vgmax}=0.1 \mathrm{pu} / \mathrm{s}, \mathrm{Rp}=0.05, \mathrm{Kp}= \\
1.163, \mathrm{Ki}=0.105, \mathrm{Kd}=0, \mathrm{Td}=0.01 \mathrm{~s}, \beta=0, \mathrm{Tw}=2.67 \\
\mathrm{~s}\end{array}$ \\
\hline Excitation System & $\begin{array}{l}\text { TLP }=0.02 \mathrm{~s}, \mathrm{Ka}=200, \mathrm{Ta}=0.001 \mathrm{~s}, \mathrm{Ke}=1, \mathrm{Te}=0, \mathrm{~Tb} \\
=0, \mathrm{Tc}=0, \mathrm{Kf}=0.001, \mathrm{Tf}=0.1 \mathrm{~s}, \mathrm{Efmin}=0, \mathrm{Efmax}=7, \\
\mathrm{Kp}=0\end{array}$ \\
\hline SSSC & $\begin{array}{l}\text { Snom }=100 \mathrm{MVA}, \text { Vnom }=500 \mathrm{kV}, \mathrm{f}=50 \mathrm{~Hz}, \mathrm{Vqmax}= \\
0.2, \mathrm{Max} . \text { rate of change of Vqref }=3 / \mathrm{s}, \mathrm{Rcnv}=0.00533, \\
\mathrm{Lcnv}=0.16, \mathrm{VDC}=40 \mathrm{kV}, \mathrm{CDC}=375 \mathrm{e}-6 \mathrm{~F}, \mathrm{KP} \text { IVR } \\
=0.00375, \text { KI_IVR }=0.1875, \mathrm{KP}_{-} \text {VddR }=0.1 \mathrm{e}-3, \\
\text { KP VdcR }=20 \mathrm{e}^{-}-3\end{array}$ \\
\hline
\end{tabular}




\section{References:}

[1]. N.G. Hingorani, "Flexible AC transmission". IEEE Spectrum, v. 30, n. 4, pp. 40-44, 1993.

[2]. N.G. Hingorani and LGyugyi, "Understanding FACTS Concepts and Technology of Flexible AC Transmission Systems", IEEE Press, New York, 2000.

[3]. Y.H. Song and A.T. Johns, Eds., "Flexible AC Transmission Systems (FACTS)", IEE Press, London, 1999.

[4]. R.M. Mathur and R.K. Varma, "Thyristor-Based FACTS Controller for Electrical Transmission Systems", IEEE Press and Wi-ley Inter-science, New York, 2002.

[5]. R. Grünbaum, M. Noroozian, and B. Thorvaldsson, "FACTS Powerful systems for flexible power transmission", ABB Rev., May 1999, 4-17.

[6]. K. Stahlkopf and M. Wilhelm, “Tighter controls for busier systems”, IEEE Spectrum, 1997, 34(4), 48-52.

[7]. K.K.Sen, "SSSC-static synchronous series compensator: theory, modelling and applications", IEEE Trans. on Power Delivery, v. 13, n. 1, 1998, pp. 241-246.

[8]. K.R. Padiyar, "Power System Dynamics - Stability and Control",Second Edition, Hyderabad: B.S. Publications, 2002.

[9]. G. Guo, Y. Wang and D.J. Hill, "Nonlinear output stabilization controlof multi-machine power systems", IEEE Trans. on Circuits and Systems,Part I, v. 47, n.1, 2000, pp. 46-53.

[10]. K.R. Padiyar, "Analysis of Sub-synchronous Resonance in PowerSystems", Kluwer Academic Publishers, Boston, 1999.

[11]. FP.DemelloandC.Concordia,"Conceptsofsynchronousmachinestabilityasaffectedbyexcitationcontrol", IEEE Trans. on Power Apparatus and Systems, v. PAS-88, 1969, pp. 316-329.

[12]. N.H. Woodley, L. Morgan and A. Sundaram, "Experience with aninverter-based Dynamics Voltage Restorer", IEEE Trans., Power De-livery, v. 14, n. 3, 1999, pp. 1181-1186.

[13]. P.T. Cheng and R.H. Lasseter, "Dynamic voltage restoration for unbalanced systems", EPRI Conf. on the Future of Power Delivery, Washington, DC, April 9-11, 1996.

[14]. J.G. Nielsen, F. Blaabjerg and N. Mohan, "Control strategies for dynamic voltage restorer compensating voltage sags with phase jump”, Appl. Power Electron. Conf. Expos, 2001; 2; pp. 1267-1273.

[15]. K.R. Padiyar and S.N.P. Anand Kumar, "Control and simulation ofDVR for improving power quality", National Power Systems Conf. (NPSC-06), I.I.T. Roorkee, December 2006.

[16]. H.W. Van Der Broeck, H.C. Skudelny and G.V. Stanke, "Analysis andrealization of a pulsewidth modulator based on voltage space vectors",IEEE Trans., Ind. Appl., v. 24, n. 1, pp. 142-150, 1988.

[17]. A. Ghosh and G. Ledwich, "Power Quality Enhancement Using Custom Power Devices", Kluwer Academic Publishers, Boston, 2002.

[18]. Sim Power Systems 4.3, User's guide.Http://www.mathworks.com/products/simpower/

[19]. B.S. Righy and R.G. Harley, "An Improved Control Scheme for a Series-capacitive Reactance Compensator Based on a VoltageSource Inverter”, IEEE Trans. Industry Applications, Vol.34, No.2, 1998, pp.355-363.

[20]. L. Sunil Kumar and A. Ghosh, "Modelling and control design of a static synchronous series compensator", IEEE Trans. Power Del., vol. 14, no. 4, pp. 1448-1453, Oct. 1999.

[21]. R. Mohan and R. K. Varma, "Thyristor-Based FACTS Controllers for Electrical Transmission Systems", Piscataway, NJ: IEEE Press, 2002.

[22]. X.P. Zhang, "Advanced modelling of the multi-control functional static synchronous series compensator (SSSC) inNewton power flow,” IEEE Trans. Power Syst., vol. 18, no. 4, pp. 1410-1416, Nov. 2003.

[23]. A. H. Norouzi and A. M. Sharaf, “An auxiliary regulator for the SSSC transient enhancement”, in Proc. IEEE 35th North Amer. Power Symp., Rolla, MO, Oct. 2003.

[24]. A. H. Norouzi and A. M. Sharaf, "Two control schemes to enhance the dynamic performance of the STATCOM and SSSC", IEEE Trans. Power Del., vol. 20, no. 1, pp.435-442, Jan. 2005.

[25]. M. S. El-Moursi and A. M. Sharaf, "Novel Controllers for the 48-Pulse VSC STATCOM and SSSC for Voltage Regulation and Reactive Power Compensation”, IEEE Transactions on Power Systems, vol.20,no.4,November 2005.

[26]. N. Magaji and M.W. Mustafa, "Optimal Thyristor Control Series Capacitor Neuro-Controller for Damping Oscillations", Journal of Computer Science, Vol.5, No.12, 2009, pp. 983-990.

[27]. K.R. Padiyar, S. Krishna and NageshPrabhu, "On-line detection of loss of synchronism is large power systems", Int. Conf. on Power Systems, Katmandu, Nepal, November 2004.

[28]. S.S. Choi, B.H. Li and D.M. Vilathgamuwa, "Dynamic voltage restoration with minimum energy injection", IEEE Trans., Power Systems, v.15, n.1, 2000, pp. 51-57.

[29]. A.K.S.N. Polisetty, “Application of custom power devices for improving power quality", M.E. Project Report, Indian Institute of Science,July 2005. 